\title{
Expression of Chirality in a Conjugated Polymer without Any Excess of Chiral Centers
}

\author{
Frederic Monnaie, Marie-Paule Van Den Eede, and Guy Koeckelberghs*
}

Laboratory for Polymer Synthesis, KU Leuven, Celestijnenlaan 200F, Box 2404, B-3001 Heverlee, Belgium

Supporting Information

ABSTRACT: Chirality is typically expressed in chiral molecules, including polymers. In this work, we demonstrate that chirality can also be expressed in a polymer molecule that does not contain any excess of chiral centers; in this specific material the chirality is evoked by a specific order of manipulations ("events"). The polymer studied is an allconjugated block copoly(3-alkylthiophene), in which the first block contains exactly the same amount of $(S)$-enantiomers as the second block $(R)$-enantiomers. Moreover, to introduce a distinct difference in solubility-required to have multiple consecutive events-the S-block is composed of $S$-monomers copolymerized with octyl-functionalized

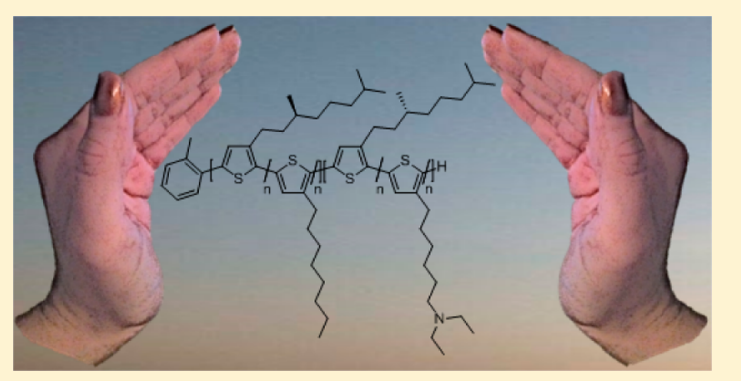
thiophene monomers, while the R-block is composed of $\boldsymbol{R}$-monomers in combination with amine-functionalized thiophene monomers. By making use of the difference in solubility of both blocks, a chiral response can be evoked from this polymer without the need of a chiral trigger.

\section{INTRODUCTION}

Chirality is omnipresent in nature. Most biological substances are chiral, and their functioning critically depends on their chiral nature. In addition, the phenomenon of homochirality is inherently associated with the creation of life. An object is chiral if two mirror images, enantiomers, exist that cannot be superimposed, for instance our hands. Expression of chirality can only be achieved if at least an excess of one enantiomer is present. Clearly, chiral effects can be observed if a large excess of one enantiomer is present, with the ultimate case of enantiopure compounds. However, sometimes very subtle effects can already result in chiral expression. For example, left- or right-handed circularly polarized light is often linked to the enantiomeric excess of certain chiral molecules, such as the L-amino acids and D-sugars, or the enantioselective photodecomposition of chiral molecules. This has intrigued different research groups over the past decades. ${ }^{1-5}$

A cooperative behavior between monomers was observed in poly(isocyanate)s for the first time, where a small enantiomeric excess or presence of chiral entities results in a larger chiral response according to the sergeants-and-soldiers or majority rules principle. ${ }^{6,7}$ Also at the nanoscale, chirality can be introduced in organic molecules. ${ }^{8,9}$ The chiral expression in regular, chiral conjugated homopolymers has already been investigated into detail, very often using circular dichroism (CD) spectroscopy, that measures the difference in absorption of left- and right-handed circularly polarized light. In a typical experiment the polymer is dissolved in a good solvent (e.g., tetrahydrofuran (THF) or chloroform $\left(\mathrm{CHCl}_{3}\right)$ ) in which the individual polymer molecules adopt an often random coil-like, achiral structure, and no chiral response is measured. If, however, a critical amount of nonsolvent (e.g., methanol
$(\mathrm{MeOH}))^{10,11}$ is added, the solution is cooled, ${ }^{12}$ or specific additives are used, ${ }^{13-15}$ the polymer molecules stack in a chiral way, hereby mimicking a one-handed helix, which leads to typical bisignate Cotton effects. We have shown that in allconjugated block copoly(thiophene)s composed of an chiral and achiral block, the chiral or achiral nature of one block can be transferred to the other block. In the case that the block which aggregates first upon addition of nonsolvent is chiral, this block imposes its chiral stacking on the second block, regardless whether it is chiral, achiral, or racemic. ${ }^{11,16-18}$ In this way, the stacking of the second block can be different from the stacking that would be found if the second block were a homopolymer. Even when the block copolymer is formed by H-bonds between the blocks, such a transfer could be observed. ${ }^{19}$ The difference in solubility of the different blocks can be turned either by varying the side chain length of the monomers of both blocks ${ }^{16,20-24}$ or by the introduction of specific functionalities in the side chains. ${ }^{18,25-35}$

The polymer studied here is an all-conjugated block copoly(3-alkylthiophene) (Figure 1), in which the first block contains exactly the same amount of $(S)$-enantiomers ( $S$ monomer) than the second block $(R)$-enantiomers ( $R$ monomer); hence, no chiral entity is present in excess. In addition, the block copolymer is designed in such a way that there is a distinct solubility difference between both blocks. The experiment is designed in such way that first one block aggregates, stacking in a chiral way, followed in a separate step by the aggregation of the second block, which adopts the same

Received: September 17, 2015

Revised: October 12, 2015

Published: October 21, 2015 


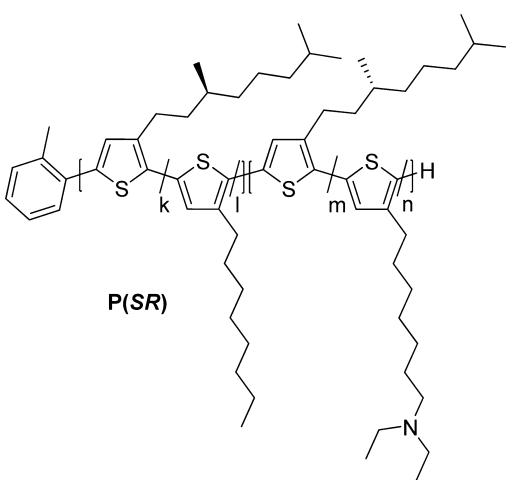

Figure 1. Structure of the all-conjugated block copoly(3-alkylthiophene) $\mathbf{P}(S R)$.

chiral stacking as the first block, hence resulting in a chiral expression.

\section{RESULTS AND DISCUSSION}

To achieve our goal, one block must selectively aggregate, while the other remains solubilized. In order to achieve this, both blocks are a copolymer of the chiral monomer and a second, achiral monomer: a linear octyl-functionalized monomer (Omonomer) in the first block and an amine-functionalized monomer (A-monomer) in the second block (Figure 2). In the

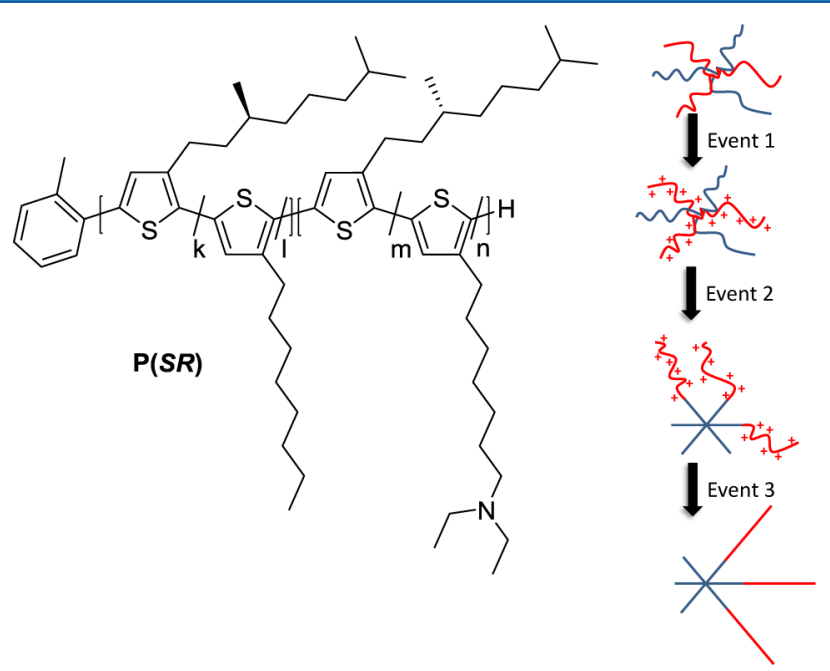

Figure 2. Left: structure of the $\mathbf{P}(S R)$ block copolymer. Right: overview of the different events; blue and red lines represent the block copolymer. The blue line indicates the copolymer composed of $\boldsymbol{S}$ - and O-monomer, and the red line represents the copolymer composed of the $\boldsymbol{R}$ - and A-monomer. Event 1: protonation of the aminefunctionalized thiophene monomers by the addition of $\mathrm{HCl}$; event 2: addition of the nonsolvent (methanol) to aggregate the $S$ containing block; event 3: addition of $\mathrm{NaOH}$ to deprotonate the ammonium salt to the amine function, upon which the $R$-block aggregates.

targeted polymer, all monomers are present in exactly equal amounts, and consequently, both blocks have an equal degree of polymerization. Note that also an o-tolyl function, which originates from the $\mathrm{Ni}$ initiator being used, is built in at the beginning of the polymer chain (vide infra). To verify whether under the conditions employed the blocks aggregate or not, two additional copolymers are prepared. One copolymer consisting of a chiral monomer and an $\mathbf{O}$-monomer and another copolymer composed of a chiral monomer and the Amonomer, mimicking the first and second block, respectively.

The idea behind the designed block copolymer is the fact that both blocks are soluble in THF, in either basic or acidic conditions, in which the amine is present as amine or ammonium salt, respectively. In a mixture of THF and a sufficient amount of methanol the first block aggregates while the second, amine-functionalized, block is soluble in acidic medium, but aggregates in basic environment. ${ }^{36}$ The experiment in order to invoke a chiral expression is designed as follows (Figure 2): first, the solution of the block copolymer in THF is acidified by $\mathrm{HCl}$ (event 1 ). Then, methanol is added until the first block aggregates (event 2). Since it is chiral, it aggregates in a chiral way. Finally, a methanolic $\mathrm{NaOH}$ solution is added (event 3 ), neutralizing the ammonium function and aggregating the second block as well.

Synthesis of the Polymers. The polymer is synthesized using a $\mathrm{Ni}(\mathrm{dppp})$ (dppp = 1,3-bisdiphenylphosphinopropane) mediated Kumada catalyst transfer polycondensation (KCTP) (Scheme 1). ${ }^{37-40}$ Exploiting the living nature of the polymerization, a mixture of the monomers for the first block is added to the initiator. When all monomers are consumed, a mixture of monomers for the second block is added and block copolymerization is realized, yielding the block copolymer $\mathbf{P}(S R)$. Since the catalytically active Ni species can move along the growing polymer backbone and realize growth at both termini, ${ }^{16,41}$ the $o$-tolyl $\mathrm{Ni}$ initiator (In1) is chosen in such way that growth is only possible in one direction-a requisite for perfect $\mathrm{AB}$ block copolymerization. The monomers are prepared in situ by a GRIM reaction on the corresponding 3alkyl-2-bromo-5-iodothiophene precursor monomers (Schemes S1 and S2). The polymerization is terminated with acidified $(\mathrm{HCl}) \mathrm{THF}$ in order to prevent disproportionation. ${ }^{42}$ As shown in Scheme 1, a part of the first block is terminated (P1), allowing the investigation of the composition, degree of polymerization and properties of the first block. In order to be able to investigate the chiral behavior of the second block, a second copolymerization using the $\mathbf{A}$ - and $S$-monomer is performed resulting in $\mathbf{P 2}$ (Scheme S2). For both copolymers $\mathbf{P 1}$ and P2, the chiral $S$-monomer is used due to the natural abundance of the compound.

A first indication of a successful block copolymerization was delivered by GPC (eluent = triethylamine/THF (5/95) toward poly(styrene) standards). A clear increase in molar mass is observed (Figure 3), while the dispersity remains low (P1: $\bar{M}_{\mathrm{n}}$ $\left.=10.5 \mathrm{~kg} / \mathrm{mol}, \emptyset=1.1 ; \mathbf{P}(S R): \bar{M}_{\mathrm{n}}=19.7 \mathrm{~kg} / \mathrm{mol}, \emptyset=1.2\right)$. GPC of P2 revealed $\bar{M}_{\mathrm{n}}=6,0 \mathrm{~kg} / \mathrm{mol}$ and $Đ=1.3$. Note that GPC is not able to provide the absolute molar masses of the polymers under study. Calibrated to poly(styrene), the molar mass of P3ATs is overestimated. ${ }^{43}$

However, both the composition and degree of polymerization can conveniently be calculated using ${ }^{1} \mathrm{H}$ NMR spectroscopy. The calculations are based on both the assignment of separate signals of the different monomers and the assignment of all possible end-groups.

Chain Length Determination and Monomer Ratio in $P 1, P(S R)$, and $\mathbf{P 2}$. In order to determine the chain length of P1 (Figure 4), the signal of the aromatic $o$-tolyl proton (a) of the initiator unit is calibrated to 1 . After this, the thiophene protons (b) are also integrated, from which the average degree of polymerization (DP) can be derived. So a DP of 28 units is obtained. The same result is obtained if the methyl group of the $o$-tolyl (d) is calibrated to 3 and the $\alpha$-methylene signals (c) are 
Scheme 1. Synthesis Overview of P1, P2, and $\mathrm{P}(S R)$ Using the $o$-Tolyl Ni Initiator

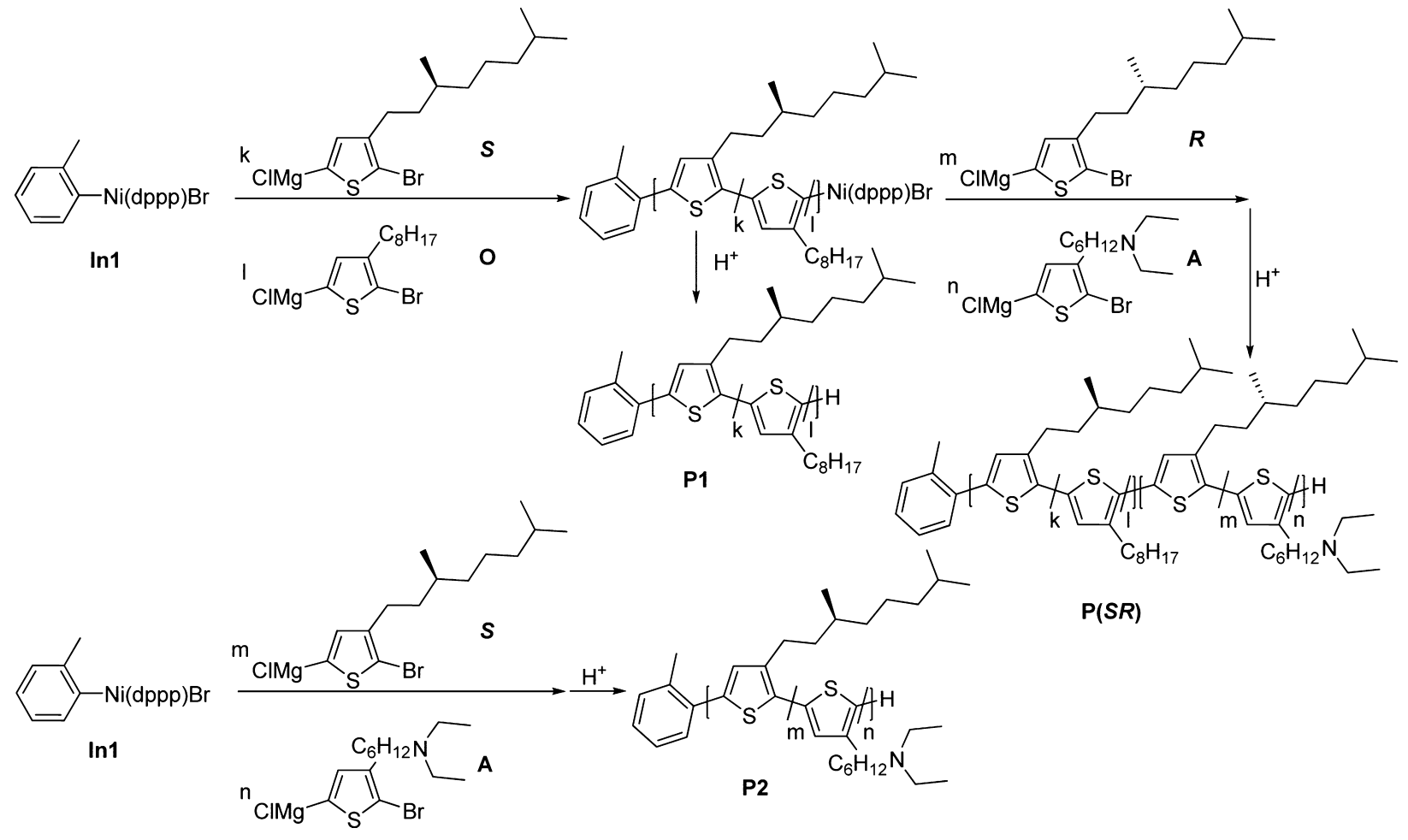

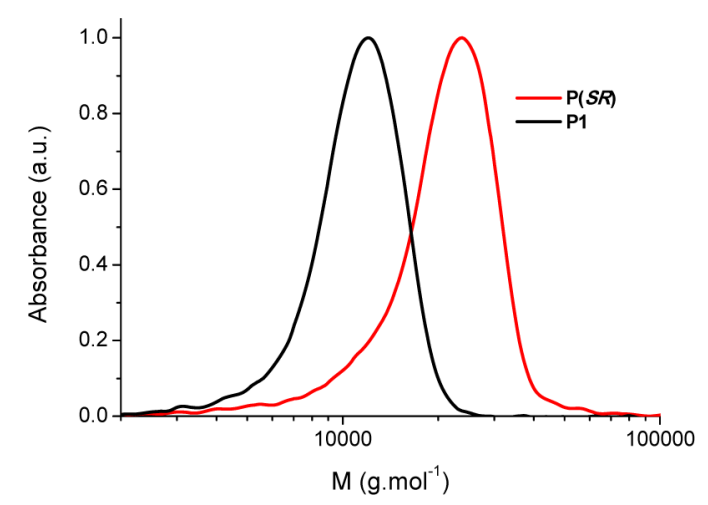

Figure 3. GPC trace of P1 (black curve) and $\mathbf{P}(S R)$ (red curve).

integrated. Now, the ratio of $\boldsymbol{S}$ - and $\mathbf{O}$-monomer can also be derived from this spectrum. The integration of the $S$ monomer's methyl group (e) indicates that 14 units are being built in. This means that 14 units are $S$ - and $\mathbf{O}$-monomer, respectively, yielding a 50/50 ratio.

As done for P1, the DP of $\mathbf{P}(S R)$ (Figure 5) can be calculated using the aromatic region ( $\mathrm{a}$ and $\mathrm{b}$ ) and gives a total DP of 56. As the DP of P1 is 28, this means that the total chain length has doubled. Next, the relative amount of the four different monomers needs to be calculated. Because of overlapping signals, four independent equations are being used. From the previous calculations we can already conclude that monomers $\boldsymbol{S}$ and $\mathbf{O}$ are in equal amounts present (eq 1). From the aromatic region, it was concluded that both blocks are equal in length (eq 2). By having a look at the aliphatic region of $\mathbf{P}(S R)$, the signal around $1 \mathrm{ppm}$ originates from 3 protons of $\boldsymbol{S}$ (d), 3 protons of $\boldsymbol{R}$ (e), and 6 of $\mathbf{A}$ (f) (eq 3). Now to set up the last of 4 equations, the region around 0.9$0.8 \mathrm{ppm}$ must be put under the scope. Here 6 protons originate from $S(\mathrm{~g})$ as well as from $\boldsymbol{R}(\mathrm{h})$ and 3 protons originate from O (i) (eq 4).

$$
\begin{aligned}
& \boldsymbol{S}=\mathbf{O} \\
& \boldsymbol{S}+\mathbf{O}=\boldsymbol{R}+\mathbf{A} \\
& 3^{*} \boldsymbol{S}+3^{*} \boldsymbol{R}+6^{*} \mathbf{A}=2.93 \\
& 6^{*} \boldsymbol{S}+6^{*} \boldsymbol{R}+3^{*} \mathbf{O}=3.70
\end{aligned}
$$

By solving these four equations, it can be stated both $S$ and $\mathrm{O}$ represent 25\%, $\boldsymbol{R}$ represents $25 \%$, and A represents $25 \%$. This means that all monomers are present for about $25 \%$ in the final block copolymer.

In order to obtain the DP of P2 (Figure 6), the aromatic region is put under the scope and the same procedure as for P1 and $\mathbf{P}(S R)$ is used. The signal of the aromatic $o$-tolyl proton (a) of the initiator unit is calibrated to 1 . After this, the thiophene protons (b) are also integrated and yields a DP of 14. To calculate the $S / A$ monomer ratio, the integration values around 1 and $0.9-0.8 \mathrm{ppm}$ are compared, while the $\alpha$-methylene protons are calibrated to 2 . The signal around $1 \mathrm{ppm}$ originates from $6 S$-monomer protons (f) (eq 5). The integration of $0.8-$ 0.9 represents $3 \mathrm{~S}$-monomer protons (d) and $6 \mathrm{~A}$-monomer protons (e) (eq 6).

$$
\begin{aligned}
& 6^{*} \boldsymbol{S}=2.75 \\
& 3 * \boldsymbol{S}+6^{*} \mathbf{A}=4.13
\end{aligned}
$$

This yields a 50/50 mixture of both $\boldsymbol{S}$ - and A-monomers in P2.

In summary, it can be concluded that the block copolymer $\mathbf{P}(S R)$ contains on average 14 chiral monomers and 14 achiral monomers in each block (i.e., $k=l=m=n=14$, Scheme 1); the block copolymer therefore consists of exactly the same amount of $\boldsymbol{S}$ - and $\boldsymbol{R}$-monomers; i.e., no excess of chiral centers is present. This is indeed confirmed by the optical rotation of $\mathbf{P}(S R)$ : it equals $[\alpha]_{\mathrm{D}}=0^{\circ} \mathrm{dm}^{-1} \mathrm{~mL} \mathrm{~g}^{-1}\left(c=0.535\right.$ in $\left.\mathrm{CHCl}_{3}\right)$. 

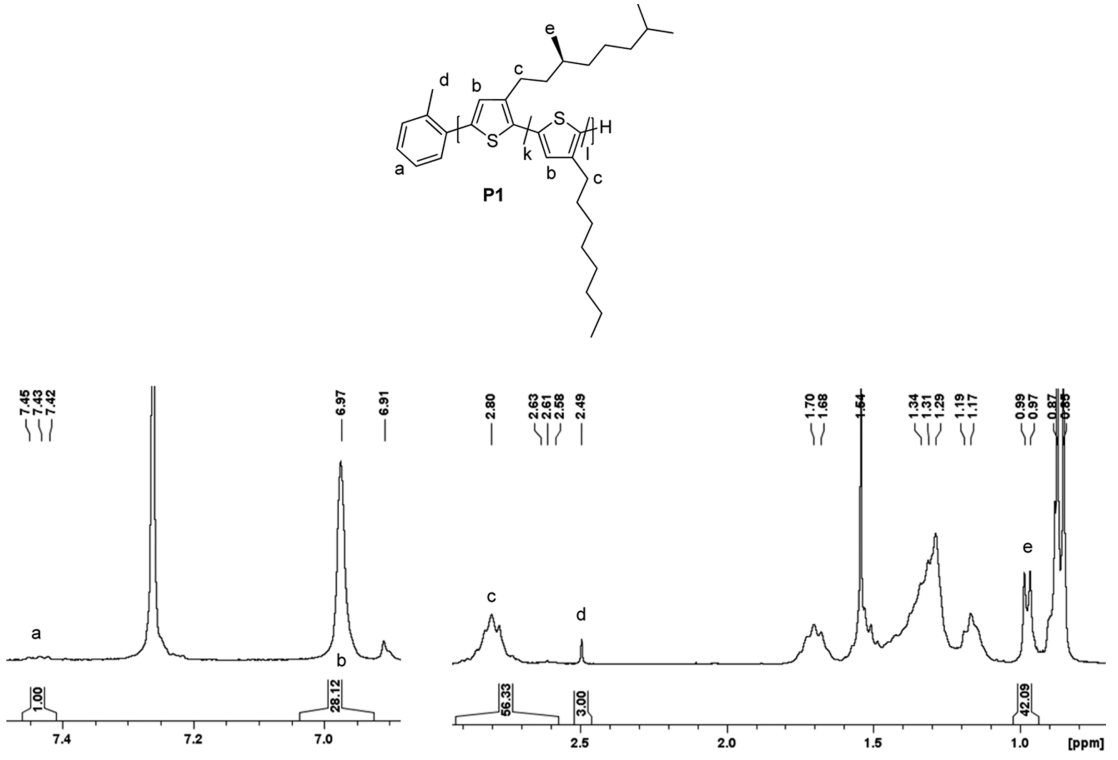

Figure 4. Overview of the ${ }^{1} \mathrm{H}$ spectrum in $\mathrm{CDCl}_{3}$ of $\mathbf{P 1}$ : the aromatic region (left) and the aliphatic region (right).

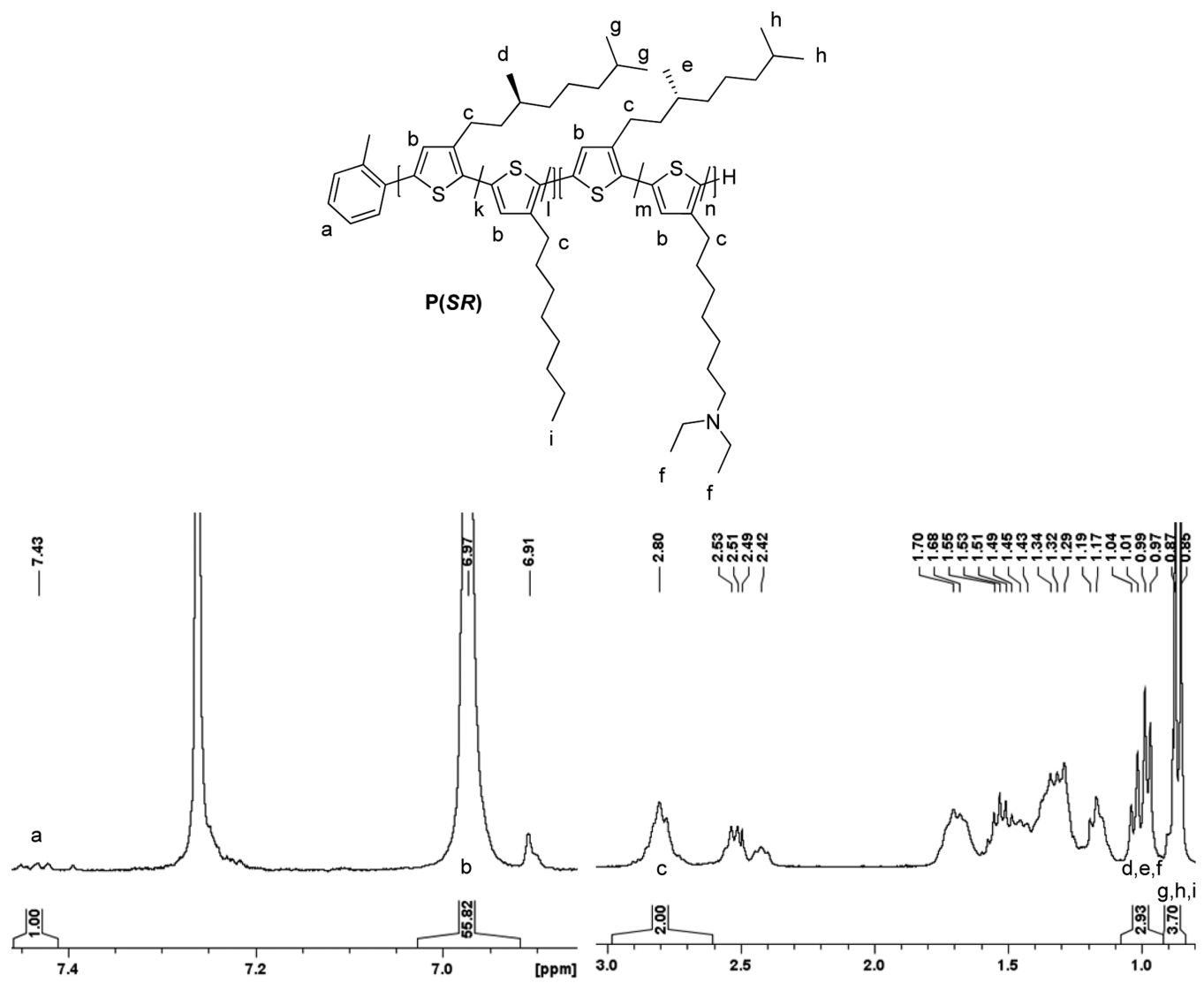

Figure 5. Overview of the ${ }^{1} \mathrm{H}$ spectrum in $\mathrm{CDCl}_{3}$ of $\mathbf{P}(S R)$ : the aromatic region (left) and the aliphatic region (right).

Expressing Chirality. Next, the concept to express chirality in $\mathbf{P}(\boldsymbol{S R})$, as described in Figure 2, is validated. First, it is verified that for the several events the specific blocks remain in solution or tend to stack. This is verified using the individual copolymers (P1 and P2). Prior to this experiment, the required amount of solvent (methanol) to aggregate P1 but to keep P2 in solution is investigated. Therefore, methanol was gradually added to an acidified THF solution. The experiment reveals that from $21 \%$ methanol chiral aggregation occurs and that $30 \%$ is required for complete aggregation (Figures S4-S6). The amount of methanol added was set to $45 \%$ to make sure the P1 copolymer was fully stacked. More than $45 \%$ of methanol was avoided to minimize the risk of flocculation of the aggregated polymers when $\mathrm{NaOH}$ is added.

Consequently, to finalize the overall experiment from event 1 to 3 as depicted in Figure 2, P1 and P2 are first dissolved in THF. After the addition of $\mathrm{HCl}(10 \mu \mathrm{L}, 12 \mathrm{M}, 120 \mu \mathrm{mol})$ (event 1 ) the UV-vis and CD spectra remain the same (Figure 


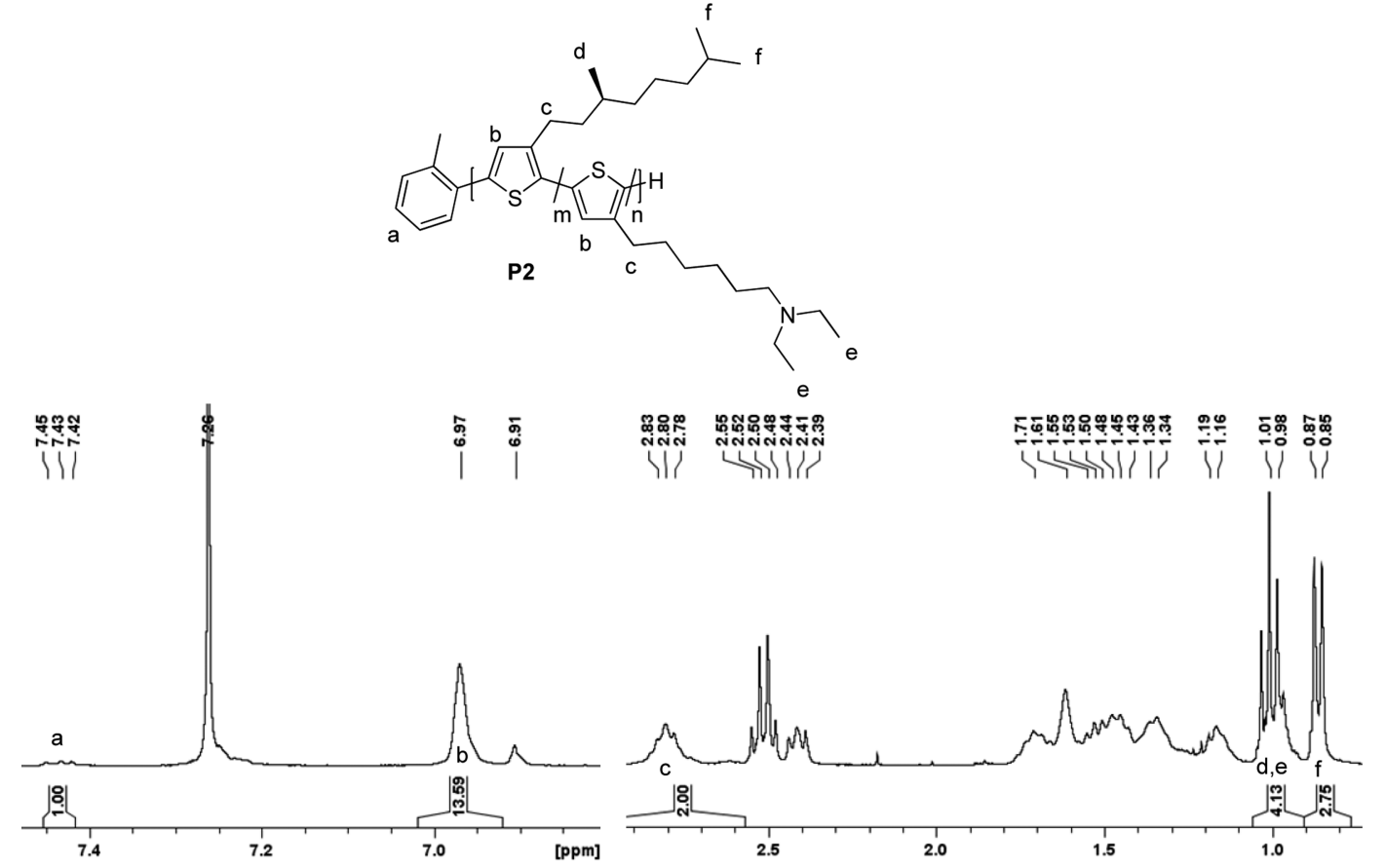

Figure 6. Overview of the ${ }^{1} \mathrm{H}$ spectrum in $\mathrm{CDCl}_{3}$ of $\mathbf{P 2}$ : the aromatic region (left) and the aliphatic region (right).
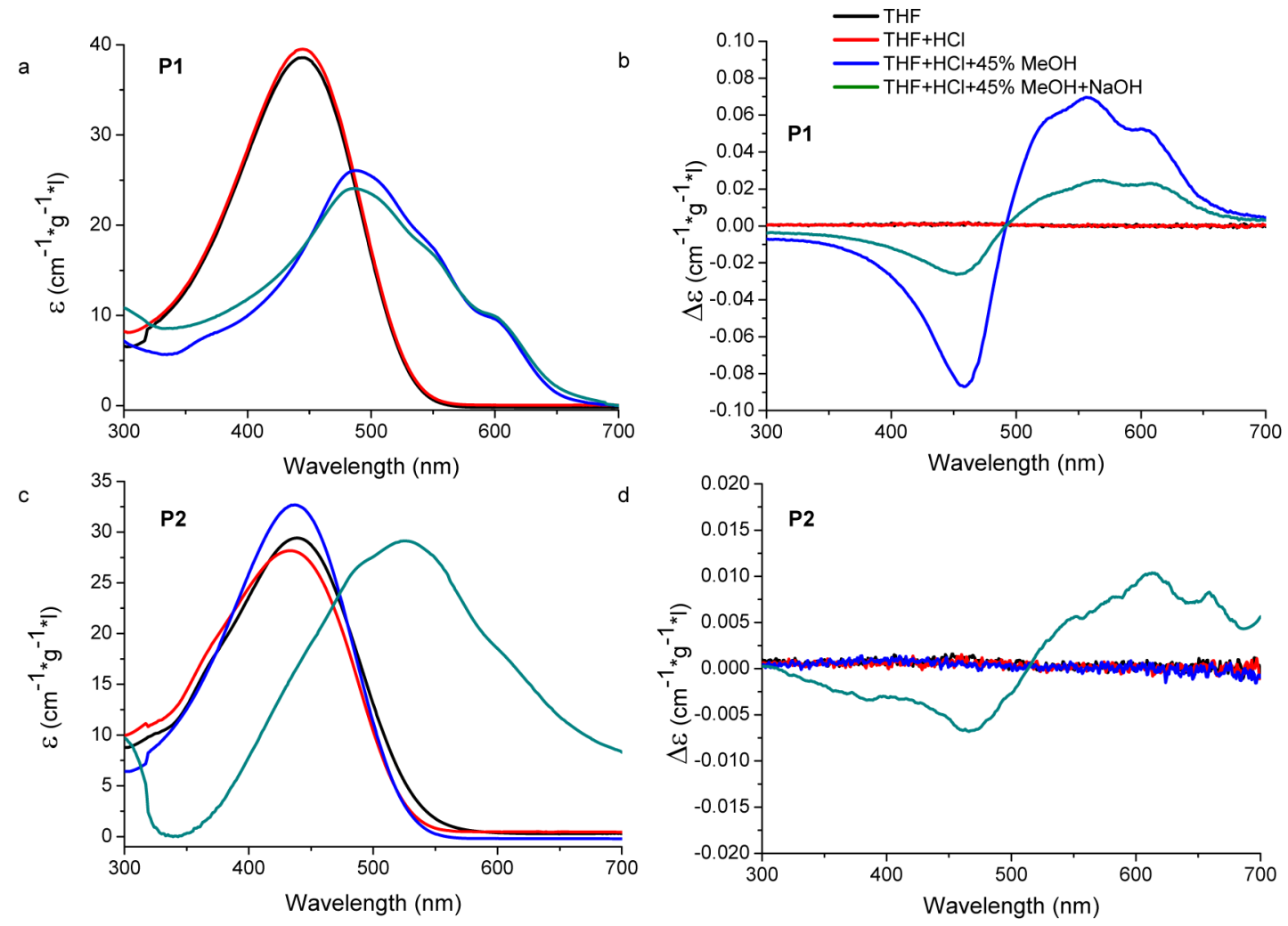

Figure 7. Overview of UV-vis (a, c) and CD (b, d) spectra measured after the different events for respectively P1 (a, b) and P2 (c, d), c = 27.3 $\mu \mathrm{g}$ / $\mathrm{mL}$ after event 1 .

7). When $45 \%$ of methanol is added, P1 shows a clear red-shift and chiral stacking, while $\mathbf{P} 2$ remains fully soluble, showing no stacking or chiral response. Finally, the ammonium salt is deprotonated in event 3 by the addition of $\mathrm{NaOH}(0.2 \mathrm{~mL}, 1$ M, $200 \mu \mathrm{mol})$ in methanol. After this event P2 shows a clear red-shift and vibrational fine structure (Figure 7).
Finally, this order of events is repeated on $\mathbf{P}(\boldsymbol{S R})$ (Figure 8). After event 1 (addition of $\mathrm{HCl}$ ), no changes appear: the UVvis spectrum shows that no aggregation occurs. After event 2 , the UV-vis spectrum clearly changes: the band at $440 \mathrm{~nm}$ partly disappears, and a new, red-shifted band with vibronic fine structure, a signature of aggregation of poly(3-alkylthiophene)s, 

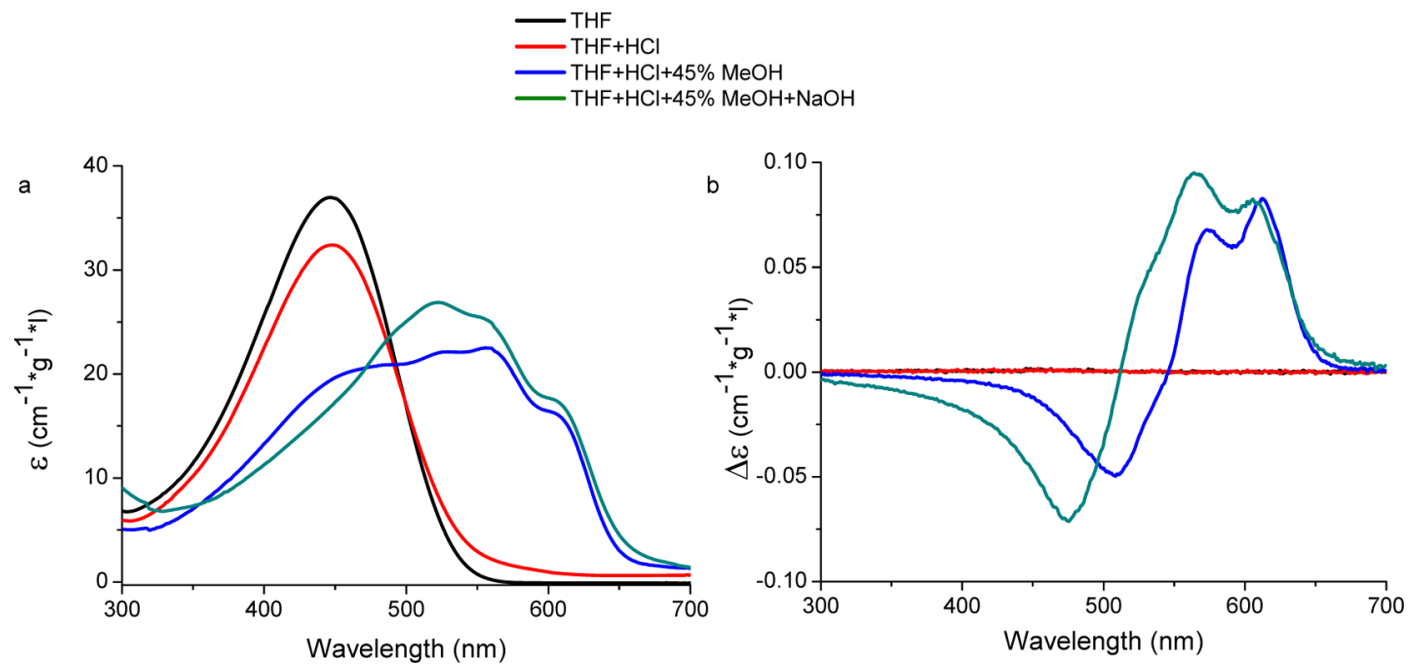

Figure 8. Overview of UV-vis (a) and CD (b) spectra measured after the different events for the $\mathbf{P}(\mathbf{S R})$ block copolymer; $c=27.3 \mu \mathrm{g} / \mathrm{mL}$ after event 1 .
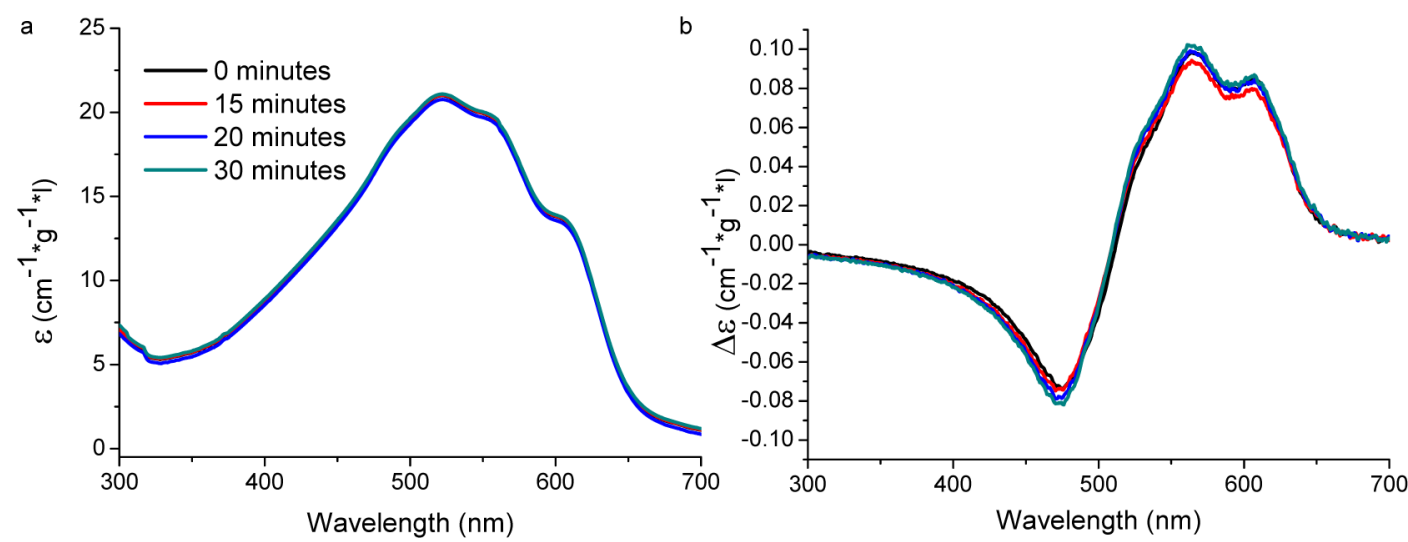

Figure 9. UV-vis (a) and CD (b) spectra of $\mathbf{P}(\mathbf{S R})$ after event 3 measured at different times $(0-30 \mathrm{~min}) ; c=14.7 \mu \mathrm{g} / \mathrm{mL}$ after event 3 .

together with a positive Cotton effect in the CD spectrum arises. Notice that there is still a part that absorbs at $440 \mathrm{~nm}$, which indicates the presence of a fraction of unstacked polymer chains. This is perfectly in line with the first block being aggregated and the second one dissolved. After event 3 (addition of $\mathrm{NaOH}$ ), the absorption band at $440 \mathrm{~nm}$ fully disappears, and the red-shifted band intensifies, pointing at aggregation of both blocks. Importantly, the CD signal does not decrease or ultimately vanishes, which would occur if the $R$ block would adopt an opposite handedness to the first block. Instead, it clearly increases in strength. Therefore, chirality is expressed in a molecule without one of the enantiomers present in excess. Note that this experiment differs from a sergeant-andsoldier or majority rules experiment. In those experiments, the formation of a chiral (super)structure from the achiral structure occurs in one step. Those experiments increase the chiral response, but they are not the origin. Our experiment occurs in multiple steps; the increase of chirality after event 3 is clearly no sergeant-and-soldier or majority rules experiment.

Expression of chirality in a nonchiral sample is not new. A typical example is bended, liquid-crystalline molecules, which tend to organize in chiral domains of opposite handedness. Hence, depending on the spot that is measured, one of the helical senses is measured. ${ }^{44,45}$ However, if the whole macroscopic sample is measured and averaged over all spots, no chirality remains present. Moreover, the boundaries are dynamic. Hence, if one particular spot is measured at different times and averaged, again no chiral signal is measured. Our experiment is clearly different: the measurements are done on a isotropic sample, and the result is therefore independent of the spot. Moreover, the chirality is also measured in function of time. Figure 9 demonstrates that the UV-vis and CD signal is stable up to $30 \mathrm{~min}$, at which time the polymer starts to flocculate.

\section{CONCLUSION}

An all-conjugated block copolymer composed of two copolymer blocks, one containing a chiral $\boldsymbol{S}$-monomer and an achiral $\mathbf{O}$-monomer and the second block containing the chiral $\boldsymbol{R}$-monomer and an achiral amine-functionalized monomer (Amonomer), was prepared by KCTP. In this polymer both blocks are composed of the same amount of repeating units and equal amount of $\boldsymbol{S}$ - and $\boldsymbol{R}$ - monomers, rendering a polymer that lacks any excess of chiral centers. Because of the presence of the amine/octyl group, the blocks have a different solubility. This was exploited in the consecutive aggregation of the two blocks. Since the block that aggregates second adopts the same chirality as the first block, a clear chiral expression can be realized although no enantiomer is present in excess or any chiral trigger is used; instead, the chiral expression originates from a specific 
order of events. Moreover, the chiral expression is stable over time and is isotropic in space.

\section{ASSOCIATED CONTENT}

\section{S Supporting Information}

The Supporting Information is available free of charge on the ACS Publications website at DOI: 10.1021/acs.macromol.5b02059.

Synthesis of P1, P2, and $\mathbf{P}(S R) ;{ }^{1} \mathrm{H}$ NMR of the polymers; UV-vis and CD spectra at different nonsolvent ratios of $\mathbf{P 1}$ and $\mathbf{P 2}$ (PDF)

\section{AUTHOR INFORMATION}

\section{Corresponding Author}

*E-mail: guy.koeckelberghs@chem.kuleuven.be (G.K.).

Notes

The authors declare no competing financial interest.

\section{ACKNOWLEDGMENTS}

We are grateful to the Onderzoeksfonds KU Leuven/Research Fund KU Leuven and the Fund for Scientific Research (FWOVlaanderen). F.M. is grateful to IWT for a doctoral fellowship.

\section{REFERENCES}

(1) Balavoine, G.; Moradpour, A.; Kagan, H. B. J. Am. Chem. Soc. 1974, 96, 5152-5158.

(2) Flores, J. J.; Bonner, W. A.; Massey, G. A. J. Am. Chem. Soc. 1977, $99,3622-3625$.

(3) Noorduin, W. L.; Bode, A. A. C.; van der Meijden, M.; Meekes, H.; van Etteger, A. F.; van Enckevort, W. J. P.; Christianen, P. C. M.; Kaptein, B.; Kellogg, R. M.; Rasing, T.; Vlieg, E. Nat. Chem. 2009, 1, 729-732.

(4) Bailey, J.; Chrysostomou, A.; Hough, J. H.; Gledhill, T. M.; McCall, A.; Clark, S.; Ménard, F.; Motohide, T. Science 1998, 281, 672-674.

(5) Huck, N. P. M.; Jager, W. F.; de Lange, B.; Feringa, B. L. Science $1996,273,1686-1688$

(6) Green, M. M.; Reidy, M. P.; Johnson, R. D.; Darling, G.; O’Leary, D. J.; Willson, G. J. Am. Chem. Soc. 1989, 111, 6452-6454.

(7) Green, M. M.; Garetz, B. A.; Munoz, B.; Chang, H. J. Am. Chem. Soc. 1995, 117, 4181-4182.

(8) Caricato, M.; Delforge, A.; Bonifazi, D.; Dondi, D.; Mazzanti, A.; Pasini, D. Org. Biomol. Chem. 2015, 13, 3593-3601.

(9) Caricato, M.; Sharma, A. K.; Coluccini, C.; Pasini, D. Nanoscale 2014, 6, 7165-7174.

(10) Bidan, G.; Guillerez, S.; Sorokin, V. Adv. Mater. 1996, 8, 157160.

(11) Langeveld-Voss, B. M. W.; Waterval, R. J. M.; Janssen, R. a. J.; Meijer, E. W. Macromolecules 1999, 32, 227-230.

(12) Langeveld-Voss, B. M. W.; Christiaans, M. P. T.; Janssen, R. A. J.; Meijer, E. W. Macromolecules 1998, 31, 6702-6704.

(13) Ho, H.-A.; Boissinot, M.; Bergeron, M. G.; Corbeil, G.; Doré, K.; Boudreau, D.; Leclerc, M. Angew. Chem., Int. Ed. 2002, 41, 15481551.

(14) Ewbank, P.; Nuding, G.; Suenaga, H.; Mccullough, R.; Shinkai, S. Tetrahedron Lett. 2001, 42, 155-157.

(15) Goto, H.; Okamoto, Y.; Yashima, E. Chem. - Eur. J. 2002, 8, 4027-4036.

(16) Verswyvel, M.; Monnaie, F.; Koeckelberghs, G. Macromolecules 2011, 44, 9489-9498.

(17) Van den Bergh, K.; Willot, P.; Cornelis, D.; Verbiest, T.; Koeckelberghs, G. Macromolecules 2011, 44, 728-735.

(18) Van den Bergh, K.; Cosemans, I.; Verbiest, T.; Koeckelberghs, G. Macromolecules 2010, 43, 3794-3800.
(19) Monnaie, F.; Ceunen, W.; De Winter, J.; Gerbaux, P.; Cocchi, V.; Salatelli, E.; Koeckelberghs, G. Macromolecules 2015, 48, 90-98.

(20) Zhang, Y.; Tajima, K.; Hashimoto, K. Macromolecules 2009, 42, $7008-7015$.

(21) Zhang, Y.; Tajima, K.; Hirota, K.; Hashimoto, K. J. Am. Chem. Soc. 2008, 130, 7812-7813.

(22) Wu, P.-T.; Ren, G.; Li, C.; Mezzenga, R.; Jenekhe, S. A. Macromolecules 2009, 42, 2317-2320.

(23) Ge, J.; He, M.; Qiu, F.; Yang, Y. Macromolecules 2010, 43, $6422-6428$.

(24) Willot, P.; Teyssandier, J.; Dujardin, W.; Adisoejoso, J.; De Feyter, S.; Moerman, D.; Leclère, P.; Lazzaroni, R.; Koeckelberghs, G. RSC Adv. 2015, 5, 8721-8726.

(25) Kim, J.; Song, I. Y.; Park, T. Chem. Commun. 2011, 47, 46974699.

(26) Song, I. Y.; Kim, J.; Im, M. J.; Moon, B. J.; Park, T. Macromolecules 2012, 45, 5058-5068.

(27) Lee, E.; Hammer, B.; Kim, J.-K.; Page, Z.; Emrick, T.; Hayward, R. C. J. Am. Chem. Soc. 2011, 133, 10390-10393.

(28) Kim, J.; Siva, A.; Song, I. Y.; Park, T. Polymer 2011, 52, 37043709.

(29) Kozycz, L. M.; Gao, D.; Hollinger, J.; Seferos, D. S. Macromolecules 2012, 45, 5823-5832.

(30) Lai, Y.-C.; Ohshimizu, K.; Takahashi, A.; Hsu, J.-C.; Higashihara, T.; Ueda, M.; Chen, W.-C. J. Polym. Sci., Part A: Polym. Chem. 2011, $49,2577-2587$.

(31) Ohshimizu, K.; Ueda, M. Macromolecules 2008, 41, 5289-5294.

(32) Ho, C.-C.; Liu, Y.-C.; Lin, S.-H.; Su, W.-F. Macromolecules 2012, $45,813-820$.

(33) Clément, S.; Meyer, F.; De Winter, J.; Coulembier, O.; Vande Velde, C. M. L.; Zeller, M.; Gerbaux, P.; Balandier, J.-Y.; Sergeyev, S.; Lazzaroni, R.; Geerts, Y.; Dubois, P. J. Org. Chem. 2010, 75, 15611568.

(34) Ouhib, F.; Khoukh, A.; Ledeuil, J.-B.; Martinez, H.; Desbriéres, J.; Dagron-Lartigau, C. Macromolecules 2008, 41, 9736-9743.

(35) Van den Bergh, K.; Huybrechts, J.; Verbiest, T.; Koeckelberghs, G. Chem. - Eur. J. 2008, 14, 9122-9125.

(36) Verswyvel, M.; Goossens, K.; Koeckelberghs, G. Polym. Chem. 2013, 4, 5310-5320.

(37) Miyakoshi, R.; Yokoyama, A.; Yokozawa, T. J. Am. Chem. Soc. 2005, 127, 17542-17547.

(38) Yokoyama, A.; Miyakoshi, R.; Yokozawa, T. Macromolecules 2004, 37, 1169-1171.

(39) Iovu, M. C.; Sheina, E. E.; Gil, R. R.; Mccullough, R. D. Macromolecules 2005, 38, 8649-8656.

(40) Sheina, E. E.; Liu, J.; Iovu, M. C.; Laird, D. W.; Mccullough, R. D. Macromolecules 2004, 37, 3526-3528.

(41) Tkachov, R.; Senkovskyy, V.; Komber, H.; Sommer, J.; Kiriy, A. J. Am. Chem. Soc. 2010, 132, 7803-7810.

(42) Miyakoshi, R.; Yokoyama, A.; Yokozawa, T. Macromol. Rapid Commun. 2004, 25, 1663-1666.

(43) Liu, J.; Loewe, R. S.; McCullough, R. D. Macromolecules 1999, $32,5777-5785$

(44) Reddy, R. A.; Tschierske, C. J. Mater. Chem. 2006, 16, 907-961.

(45) Jang, Y.; Balachandran, R.; Keith, C.; Lehmann, A.; Tschierske, C.; Vij, J. K. Soft Matter 2012, 8, 10479-10485. 